BMJ Open Sport \& Exercise Medicine

\title{
The training type influence on male elite athletes' ventilatory function
}

\author{
Tijana Durmic, ${ }^{1}$ Biljana Lazovic Popovic, ${ }^{2,3}$ Mirjana Zlatkovic Svenda, ${ }^{3,4}$ \\ Marina Djelic, ${ }^{5}$ Vladimir Zugic, ${ }^{3,6}$ Tamara Gavrilovic, ${ }^{7}$ Zoran Mihailovic, ${ }^{1}$ \\ Marija Zdravkovic, ${ }^{3,8}$ Roman Leischik ${ }^{9}$
}

To cite: Durmic T, Lazovic Popovic B, Zlatkovic Svenda M, et al. The training type influence on male elite athletes' ventilatory function. BMJ Open Sport Exerc Med 2017;3:e000240. doi:10.1136/bmisem-2017000240

Accepted 20 June 2017 CrossMark

${ }^{1}$ Institute of Forensic Medicine, School of Medicine, University of Belgrade, Belgrade, Serbia ${ }^{2}$ University Clinical Center 'Zemun', Belgrade, Serbia ${ }^{3}$ School of Medicine, University of Belgrade, Belgrade, Serbia

${ }^{4}$ Institute of Rheumatology, Belgrade, Serbia

${ }^{5}$ Institute of Medical

Physiology, School of Medicine, University of Belgrade, Belgrade, Serbia ${ }^{6}$ Clinic for Lung Diseases, Clinical Center of Serbia, Belgrade, Serbia

${ }^{7}$ Serbian Institute of Sport and Sports Medicine, Belgrade, Serbia

${ }^{8}$ University Hospital Medical Center 'Bezanijska Kosa', Belgrade, Serbia

${ }^{9}$ Department of Cardiology/ Prevention and Sports Medicine, School of Medicine, University Witten/ Herdecke, Hagen, Germany

Correspondence to Dr Tijana Durmic, Institute of Forensic Medicine, Belgrade, 11000, Serbia; tijana. durmic@med.bg.ac.rs

\section{ABSTRACT}

Background/aim To assess and compare measured ventilatory volumes (forced expiratory volume in $1 \mathrm{~s}$ $\left(\mathrm{FEV}_{1}\right)$, peak expirium flow (PEF) and maximal voluntary ventilation (MVV)), ventilatory function capacities (forced vital capacity (FVC) and vital capacity $(\mathrm{VC})$ ) and $\mathrm{FEV}_{1} \mathrm{NC}$ ratio in a sample of power and endurance elite athletes and their age-matched and sex-matched sedentary control group.

Methods A cross-sectional study was applied on male elite athletes $(n=470)$ who were classified according to the type of the predominantly performed exercise in the following way: group 1: endurance group $(E G=270)$, group 2: power athletes group ( $\mathrm{SG}=200)$ and group 3: sedentary control group ( $\mathrm{CG}=100)$. The lung VC, FVC, FEV $1, \mathrm{FEV}_{1} / \mathrm{FVC}$ ratio, PEF and MVV were measured in all of the observed subjects, who were also classified with regard to body mass index (BMI) and the percentage of the body fat (BF\%).

Results The CG had the highest BF\% value, while the endurance group had the lowest $\mathrm{BMI}$ and $\mathrm{BF} \%$ value, which is significantly different from the other two groups $(p<0.05)$. The observed values of VC, FVC and $\mathrm{FEV}_{1}$ in the $\mathrm{EG}$ were significantly higher than those from the other two groups $(p<0.05)$. There were no differences concerning the observed $\mathrm{FEV}_{1} / \mathrm{FVC}$ ratio. Conclusions A continued endurance physical activity leads to adaptive changes in spirometric parameters (VC, FVC and $\mathrm{FEV}_{1}$ ), highlighting the fact that there is a need for specific consideration of different respiratory 'pattern' development in different types of sport, which also has to be further evaluated.

\section{INTRODUCTION}

The cardiovascular system adaptation on different sport types training and the reversibility of this process following the training cessation in adults is a well-known fact. ${ }^{1}{ }^{2}$ However, the healthy subject respiratory system is not considered a limiting factor for the high-intensity endurance exercise, as it is commonly thought that the capacity of the pulmonary system is sufficient to cope with the higher ventilation and gas exchange demands. ${ }^{1}$ In addition, although it is certain that high-intensity flow-repetitive ventilatory muscle training

\section{What are the new findings?}

- This is a large pioneering cross-sectional study that included 470 male elite athletes and examined and compared measured ventilatory volumes (forced expiratory volume in $1 \mathrm{~s}\left(\mathrm{FEV}_{1}\right)$, peak expirium flow and maximal voluntary ventilation), ventilatory function capacities (forced vital capacity (FVC) and vital capacity (VC)) and $\mathrm{FEV}_{1} N \mathrm{NC}$ ratio in a sample of power and endurance elite athletes and their age-matched and sex-matched sedentary control group.

- Overall, we found, among other differences, that values of VC, FVC and $\mathrm{FEV}_{1}$ in the endurance athletes were significantly higher than those from the other two groups.

How might it impact on clinical practice in the near future?

Our results have indicated that chronic endurance physical activity leads to adaptive changes in spirometric parameters, leading to specific 'respiratory pattern' according to the sport type. This can be particularly important because it can contribute to the new insights into the exerciseinduced hypoxaemia diagnostics and rehabilitation, even in young, endurance athletes.

increases vital capacity (VC) and total lung capacity, recent studies have shown that respiratory system may not show any adaptation to regular physical activity at all. ${ }^{1}$

There are a few studies addressed to the physical activity effect on the pulmonary function and ventilatory test parameters in different athlete groups. ${ }^{3}{ }^{4}$ Other studies aiming at describing of the pathological respiratory conditions, such as pulmonary oedema and pulmonary blood-gas barrier damage, particularly during maximal effort exercises, are also presented. ${ }^{5}{ }^{6}$ This fact is important, as it can contribute to the exercise-induced hypoxaemia, even in young, endurance athletes. ${ }^{7} 8$ Different exercise 
Table 1 Demographic and anthropometric characteristics for both groups of athletes (endurance and power) and the control group

\begin{tabular}{|c|c|c|c|c|c|c|}
\hline & \multicolumn{4}{|l|}{ Athletes } & & \\
\hline & \multicolumn{2}{|l|}{ Endurance } & \multicolumn{2}{|l|}{ Power } & \multicolumn{2}{|l|}{ Controls } \\
\hline & Mean (SD) & Range & Mean (SD) & Range & Mean (SD) & Range \\
\hline Age (years) & 20.61 (3.68) & $17-33$ & $23.28(4.27)$ & $17-35$ & 23.12 (4.05) & $17-32$ \\
\hline Body mass (kg) & 75.04 (8.70) & $51-99$ & $78.46(16.05)^{\star} \dagger$ & $49-141$ & 73.28 (11.53) & $50-105$ \\
\hline Body height (cm) & $181.46(6.80)^{* \dagger}$ & $161-201$ & 177.68 (8.82) & 160-198 & 177.48 (8.07) & $160-196$ \\
\hline BMI $\left(\mathrm{kg} / \mathrm{m}^{2}\right)$ & $22.73(1.70)$ & $17.82-28.84$ & $24.67(3.50)^{* \dagger}$ & 19.23-39.70 & $23.16(2.78)$ & $18.25-33.14$ \\
\hline $\mathrm{BSA}\left(\mathrm{m}^{2}\right)$ & $1.94(0.14)^{\star}$ & $1.51-2.30$ & $1.96(0.24)^{\star}$ & $1.48-2.72$ & $1.90(0.18)$ & $1.5-2.28$ \\
\hline $\mathrm{BF}(\%)$ & $10.98(3.15)^{\star \dagger}$ & $7.00-22.20$ & $13.11(5.23)^{\star}$ & $7.00-36.10$ & 15.06 (6.34) & $8.10-35.10$ \\
\hline
\end{tabular}

${ }^{*} \mathrm{p}<0.05$ as compared with controls.

$\dagger \mathrm{p}<0.05$ between endurance and power athletes.

$\mathrm{BF} \%$ percentage of body fat; BMI, body mass index; BSA, body surface area.

sport studies suggest that the small airway function impairment can be detected in the absence of the respiratory symptoms, even after the cessation of activity. ${ }^{9}$ Endurance athletes have higher prevalence of asthma, compared not only with sedentary group, but also compared with power athletes. ${ }^{10}$

Bearing in mind the lack of normative respiratory parameters predictive values for the athletic population, spirometry interpretation could lead to misclassification, or even misdiagnosis of pulmonary disorders in the elite athlete's clinical evaluation.

The aim of this study was therefore to assess and compare measured ventilatory volumes (forced expiratory volume in $1 \mathrm{~s}\left(\mathrm{FEV}_{1}\right)$, peak expirium flow (PEF), maximal voluntary ventilation (MVV)), ventilatory function capacities (forced vital capacity (FVC) and VC) and $\mathrm{FEV}_{1} / \mathrm{VC}$ ratio in a sample of power and endurance elite athletes and their age-and sex-matched sedentary control group.

\section{METHODS}

This cross-sectional study has included 470 male elite athletes (aged 17-35 years), referred for the sport preparticipation medical examination (from January 2012 to June 2013). They were divided into two groups according to the type of exercise they have mostly performed: group 1 engaged 270 endurance athletes (all football players) and group 2 embraced 200 power athletes (15 weightlifters, 30 wrestlers, 40 boxers, 20 body builders, 20 kick boxers, 27 judo, 22 taekwondo, 15 kendo, 7 savate and 4 kyokushinkai karate athletes). The inclusion criteria were the following:

1. national or international level tournament participation

2. 15 or more hours of training per week

3 . current and past non-smokers

4. with no medications at the time of testing

5 . with no concomitant diseases.
Group 3 was the control group (CG), consisting of 100 sedentary controls, conditioned of not being connected with any particular type of sport, without a regular exercise programme and with no history of the respiratory disease. After being informed about the possible investigation risks, all of the participants gave the written informed consent. All of the procedures were approved by the ethics committee of the University of Belgrade School of Medicine, conducted in accordance with the World Medical Association Declaration of Helsinki.

\section{Anthropometric parameters}

Before undergoing the test, participants were asked to take a light dinner (before 20:00) on the day before and not to eat food or drink caffeine beverages on the test day. The body weight (BW) and body fat percentage $(\mathrm{BF} \%)$ were measured on a scale with $0.01 \mathrm{~kg}$ readability (BC-418 Segmental Body Composition Analyzer, Tanita, USA), with participants wearing minimal clothes and being barefoot. The body height (BH) was measured with a stadiometer with $0.1 \mathrm{~cm}$ readability (Seca 214 Portable Stadiometer, Cardinal Health, Ohio, USA) according to the described standardised procedures. ${ }^{11}$ The body mass index (BMI) was calculated as the ratio of the body mass (kilograms) divided by body height (metres) squared. The body surface area (BSA) was calculated using the Mosteller formula and expressed as squared metres.

\section{Spirometry}

Before using the test, subjects were asked not to smoke, exercise, consume alcohol, caffeine beverages or use theophylline or $\beta$-agonist inhalers. The test was performed in laboratory setting, at the same time of the day (07:30-9:00), using the same instruments and technique. The spirometry was performed following the ATS/ERS Task Force Recommendations. ${ }^{12}$ 
Table 2 Ventilatory parameters for both groups of athletes (endurance and power) and the control group; description and estimated group differences (linear regression model adjusted for the body mass index)

\section{Groups}

Mean (SD)

Athletes

\begin{tabular}{|c|c|c|c|c|}
\hline \multirow[t]{7}{*}{ Observed } & & Endurance & Power & Controls \\
\hline & FVC (L) & $5.21(0.82)^{\star} \dagger$ & $5.00(0.90)$ & $4.92(0.94)$ \\
\hline & $\mathrm{FEV}_{1}(\mathrm{~L})$ & $4.59(0.69)^{\star} \dagger$ & $4.35(0.71)$ & $4.39(0.87)$ \\
\hline & PEF (L) & $9.20(2.03) \ddagger$ & $9.20(1.72)$ & $9.20(2.06)$ \\
\hline & VC (L) & $5.37(0.80)^{\star} \dagger$ & $5.18(0.94)$ & $5.14(1.00)$ \\
\hline & $\mathrm{FEV}_{1} / \mathrm{NC}$ & $85.90(8.41)$ & $84.16(7.00)$ & 84.54 (6.99) \\
\hline & MVV (L) & $160.72(35.41) \ddagger$ & 157.11 (33.09) & $161.19(35.82)$ \\
\hline
\end{tabular}

${ }^{*} \mathrm{p}<0.01$ endurance compared with power athletes. $\dagger p<0.01$ endurance compared with control group. $\pm \mathrm{p}<0.05$ endurance compared with power athletes.

FVC, forced vital capacity; $\mathrm{FEV}_{1}$, forced expiratory volume in $1 \mathrm{~s}$; L, litres; MVV, maximum voluntary ventilation; PEF, peak expiratory flow rate; VC, vital capacity.

Measurements were carried out under standard environmental conditions: comfort temperature (between $18^{\circ} \mathrm{C}$ and $22^{\circ} \mathrm{C}$ ), the atmospheric pressure of $760 \mathrm{~mm} \mathrm{Hg}$ and a relative atmospheric humidity of $30 \%-60 \%$. The temperature, humidity and atmospheric pressure were continuously measured at the lab. Static lung function measurements were performed using the turning pneumotach Pony FX (Cosmed Pulmonary Function Equipement, Italy). Subjects performed the test in a sitting position with a nose clip in place and the spirometer held in one hand. After maximal inhalation, a subject was asked to seal his lips around the mouthpiece and exhale as hard and as fast as possible, being encouraged to continue exhaling for at least $1 \mathrm{~s}$ so that $\mathrm{FEV}_{1}$ could be measured. Tests were repeated at a minimum of three times or until the two highest values were recorded. Direct measurements included FVC (litres), $\mathrm{FEV}_{1}$ (litres) and PEF (litres/ second). The forced expiratory ratio (\%) was also calculated $\left(\left(\mathrm{FEV}_{1} / \mathrm{FVC}\right) \times 100\right)$. MVV was done at a $15 \mathrm{~s}$ time period before being extrapolated to a value for $1 \mathrm{~min}$ expressed as litres/minute.

\section{Statistics}

First, the examined groups were separately evaluated for age, body mass, body height, BMI, BSA and body fat, all of which were expressed in means (SD) as well as estimated in differences by using the independent samples T-test. Second, with regard to the measured ventilatory volumes $\left(\mathrm{FEV}_{1}, \mathrm{PEF}\right.$ and MVV) and ventilatory function capacities (FVC and VC), differences in between athletes and between each of the athletes group and the control group were assessed by using a linear regression model adjusted for the identified confounding factors. All of the statistic tests were two sided with the level of significance set at 0.05 , performed by using the SPSS software, V. 20.0.

\section{RESULTS}

Demographic and anthropometric data are shown in table 1 .

Power athletes had significantly higher BM and BMI $(\mathrm{p}<0.05)$, when compared with endurance athletes and controls, both. Although power athletes had the highest BMI value, the controls had the highest BF\% value, which is significantly higher than both of the athletes groups $(p<0.05)$. Additionally, the endurance athletes have the lowest BMI value and they had a lower $\mathrm{BF} \%$ value $(\mathrm{p}<0.05)$ than power athletes and controls. Body height was significantly higher in endurance athletes, as compared with power athletes and controls $(\mathrm{p}<0.05)$. Power athletes had the highest BSA values, significantly higher when compared with endurance athletes and the control group, both $(\mathrm{p}<0.05)$.

When controlled for the confounding effect of the BMI (integrating the BW and the body height, identified as confounders), highly significant difference was found with regard to the observed values of the FVC, $\mathrm{FEV}_{1}$ and $\mathrm{VC}$ between endurance and power group, as well as between endurance and controls, and borderline significance was presented in PEF and MVV when comparing endurance and power group, while this difference was not noted in between the power group and controls (table 2).

\section{DISCUSSION}

According to the results of the present study, the endurance athletes' respiratory parameters are highly significantly different in the observed values of the 
$\mathrm{FVC}, \mathrm{FEV}_{1}$ and $\mathrm{VC}$ and borderline significantly different with regard to PEF and MVV from the power athletes, while this fact was not reflected in the mostly used and interpreted pulmonary function parameter$\mathrm{FEV}_{1} / \mathrm{VC}$.

Namely, there is evidence that exercise may affect spirometric indices leading to higher $\mathrm{FEV}_{1}$ and $\mathrm{FVC}$ even during mild exercise, especially during long-term endurance type of physical activity. ${ }^{13}$ These adaptive changes are even higher in elite athletes, with up to $20 \%$ higher $\mathrm{FEV}_{1}$ values when compared with sedentary population. ${ }^{12}$ This could be explained by the airways resistance reduction, increased alveolar expansion and total lung elasticity enhancement caused by continuous physical activity. Moreover, endurance physical activity also improves the strength of respiratory muscles. ${ }^{2} 14$

The results of this study support the work that has found increased pulmonary function parameters in athletes when compared with sedentary controls. ${ }^{15} 16$ For example, athletes in the Myrianthefs and associates study also had higher pulmonary function capacities than their age-matched controls. With regard to the previously mentioned, although the majority of the examined observed respiratory parameters values were higher in athletes in our study, they were similar between groups. ${ }^{17}$ Moreover, endurance athletes had significantly higher levels of $\mathrm{FEV}_{1}, \mathrm{FVC}$ and $\mathrm{VC}$ when compared with the power group and the control group, while this difference was not noted in between the latter two groups. This result is in contrast with the previously published studies results, reporting that all athletes, regardless of the sport type, had higher lung volumes than the sedentary population. ${ }^{13}$

According to our results, there was no difference in $\mathrm{FEV}_{1} / \mathrm{FVC} \%$ between any of the athletes groups and the control group. Although the values of $\mathrm{FEV}_{1}$, FVC, MVV and PEF were lower in sedentary controls than in the power group, the $\mathrm{FEV}_{1} / \mathrm{FVC} \%$ was higher. This suggests that elite athletes had more reserve capacity. This may explain why the respiratory function changes are often seen for endurance and power athletes, but not seen in sedentary controls. ${ }^{12}$

However, the ventilatory capacity differences were found between endurance athletes and their agematched and-sex-matched controls, as well as between endurance athletes and the power athletes. On the contrary of what was expected, the power athletes' ventilatory capacity did not differ from that of the control group. To the best of the authors' knowledge, this could be explained by the provocative nature of the repeated exercise-induced hyperpnoea in combination with irritant-laden environment conditions that may occur in some sport types. Our results also show that, aside from the most commonly used anthropometric predictive factors for the respiratory parameters such as body height and BW, we should think about some other more precise anthropometric parameters that may predict lung volumes in athletes. ${ }^{18}$
Our results and the literature data suggesting that, in addition to factors such as age, body weight, height and gender, some other body composition parameters such as fat free mass or waist measurement could be of a great importance for predicting results of pulmonary function tests during pulmonary function assessment. ${ }^{14}$ Namely, Maiolo et al showed signifficant correlation between FVC and BMI, waist measurement and fat mass, suggesting that fat accumulation in thoracic and abdominal cavities arise changes in respiratory function including sluggish thoracic movements and pulmonary compliance in thoracic cavity, reduced inspiratory capacity and falling of diaphragm. ${ }^{14} 19$

Also, some studies suggest fat-free mass (FFM), thoracic diameter and trunk length may equally be important lung volume predicting parameters in athletes. ${ }^{14}{ }^{18}$ So, there is no doubt that both anatomical and mechanical factors may account for lung volume differences in different sport athletes. ${ }^{20}$

According to our study that included diametrically diverse athletes considering type and intensity of the performed exercise, the endurance athletes had significantly higher absolute spirometric values as compared with the power athletes and controls.

Also, previous studies pointed on the fact that besides age, gender, ethnicity and more common anthropometric parameters (height and weight), there are some other factors that could influence respiratory function in elite athletes. Namely, the equilibrium between chest elasticity and strength of the thoracic and abdominal muscles, in one side and individual posture play an important role. Moreover, physical activity and specific training regime activates the whole body system muscles, which results in particular respiratory adaptation. ${ }^{2}$

Higher $\mathrm{FEV}_{1}$ in endurance athletes could be explained by the lowest $\mathrm{BF} \%$ value, pointing out obesity as a limiting factor for $\mathrm{FEV}_{1}$ in elite athletes. ${ }^{3}$ Experimental studies have shown that endurance aerobic training leads to PEF improving. ${ }^{3}{ }^{4}$ Aside from the generally accepted fact that physical activity leads to cardiorespiratory fitness level improving, it was demonstrated that frequent and prolonged periods of hyperpnoea during physical activity (characterised certain high-level sports), may also be harmful to pulmonary health. ${ }^{21}$ This fact should be remembered, bearing in mind that even mild exercise may improve lung volumes in general population, with more prominent changes in elite athletes. ${ }^{22} 23$

This becomes evident in elite athletes spirometric measurement. Namely, current American Thoracic Society/European Respiratory Society reference values are derived from general population, which may be important to consider, especially in a case of elite athlete airway dysfunction, presented as exercise-induced bronchoconstriction (EIB), seen in up to $50 \%$ of athletes who are neither with atopic nor asthmatic constitution. ${ }^{2}$

However, all of the subjects in our study had FVC and $\mathrm{FEV}_{1} / \mathrm{FVC}$ within the normal range. Clinical 
manifestation of EIB is most commonly seen as a mild impairment of the respiratory performance. Also, EIB is more prevalent in athletes than clinically recognised, causing high unrecognition level or even misdiagnosis. There is strong evidence on interaction between ventilatory requirements duration and characteristics and airway obstruction in different sports. ${ }^{1021}$ Most of the recent studies in this area report diverse data in the area of different respiratory 'pattern' development in different sport types. ${ }^{2425}$

Approximately same values of major respiratory parameters across all age groups and sport types in athletes and controls are particularly important, as sport physicians often use predicted spirometric indices when explaining the observed ones, particularly in case when an athlete has certain respiratory symptoms including dyspnoea, cough and wheezing. Breathing mechanism differences play significant challenge because of inherent difficulties in endurance and power athletes comparing, due to known differences in body composition, as well as due to incomplete usage of the most appropriate way to explain current ATS/ERS reference guidelines that describe respiratory parameters. The fact is that cardiovascular and skeletal system adapt to exercise. It is still not clear enough why the pulmonary structures adaptation is not only substantially lesser than other links in the oxygen transport system, and also why it differs according to the sport type.

In conclusion, our results have indicated that chronic endurance physical activity leads to adaptive changes in spirometric parameters ( $\mathrm{VC}, \mathrm{FVC}, \mathrm{FEV}_{1}$ and $\mathrm{FEV} /$ $\mathrm{VC})$. Since there were no significant differences concerning these parameters in power athletes and physically inactive individuals, it was concluded that the adaptation of the ventilatory parameters could be influenced by the sport type.

Once again, our study highlights the need for further meticulous evaluation of different respiratory 'pattern' development in different types of sport.

Acknowledgements The authors express their deepest thanks to The Serbian Institute of Sport and Sports Medicine for their effort to accomplish this study.

Contributors MZ, TD, RL and BLP conceived the idea and guided experiments. TD, TG and VZ prepared tips/samples and performed experiments. TG conducted all measurements of the athletes. MZ, ZM, MD and MZS discussed about results. TD wrote the manuscript with inputs from other authors. All authors discussed the results and commented on the manuscript.

Competing interests None declared.

Patient consent Obtained

Ethics approval School of Medicine, University of Belgrade.

Provenance and peer review Not commissioned; externally peer reviewed.

Data sharing statement This study does not contain any additional unpublished data that are available to other person or organization.

Open Access This is an Open Access article distributed in accordance with the Creative Commons Attribution Non Commercial (CC BY-NC 4.0) license, which permits others to distribute, remix, adapt, build upon this work noncommercially, and license their derivative works on different terms, provided the original work is properly cited and the use is non-commercial. See: http:// creativecommons.org/licenses/by-nc/4.0/

(C) Article author(s) (or their employer(s) unless otherwise stated in the text of the article) 2017. All rights reserved. No commercial use is permitted unless otherwise expressly granted.

\section{REFERENCE}

1. Amann M. Pulmonary system limitations to endurance exercise performance in humans. Exp Physiol 2012;97:311-8.

2. Leischik R, Dworrak B. Ugly duckling or Nosferatu? Cardiac injury in endurance sport - screening recommendations. Eur Rev Med Pharmacol Sci 2014;18:3274-90.

3. Brown PI, Venables HK, Liu H, et al. Ventilatory muscle strength, diaphragm thickness and pulmonary function in world-class powerlifters. Eur J App/ Physiol 2013;113:2849-55.

4. Degens H, Rittweger J, Parviainen T, et al. Diffusion capacity of the lung in young and old endurance athletes. Int J Sports Med 2013;34:1051-7.

5. Doherty M, Dimitriou L. Comparison of lung volume in Greek swimmers, land based athletes, and sedentary controls using allometric scaling. Br J Sports Med 1997;31:337-41.

6. Caillaud C, Serre-Cousiné O, Anselme F, et al. Computerized tomography and pulmonary diffusing capacity in highly trained athletes after performing a triathlon. J Appl Physiol 1995;79:1226-32.

7. West JB. Throughts on the pulmonary gas-barrier. Am J physiol 2003;285:501-13.

8. Dempsey JA, McKenzie DC, Haverkamp HC, et al. Update in the understanding of respiratory limitations to exercise performance in fit, active adults. Chest 2008;134:613-22.

9. Nielsen HB. Arterial desaturation during exercise in man: implication for $\mathrm{O} 2$ uptake and work capacity. Scand J Med Sci Sports 2003;13:339-58.

10. Rong $\mathrm{C}$, Bei $\mathrm{H}$, Yun $\mathrm{M}$, et al. Lung function and cytokine levels in professional athletes. J Asthma 2008;45:343-8.

11. Kippelen $\mathrm{P}$, Caillaud $\mathrm{C}$, Robert $\mathrm{E}$, et al. Effect of endurance training on lung function: a one year study. Br J Sports Med 2005;39:617-21.

12. Cheng YJ, Macera CA, Addy CL, et al. Effects of physical activity on exercise tests and respiratory function. $\mathrm{Br} J$ Sports Med 2003;37:521-8.

13. Myrianthefs $P$, Grammatopoulou I, Katsoulas T, et al. Spirometry may underestimate airway obstruction in professional Greek athletes. Clin Respir J 2014;8:240-7.

14. Park JE, Chung JH, Lee $\mathrm{KH}$, et al. The effect of body composition on pulmonary function. Tuberc Respir Dis 2012;72:433-40.

15. Miller MR, Hankinson J, Brusasco V, et al. ATS/ERS Task force: standardization of spirometry. EurRespir J 2005;26:319-38.

16. Galanis N, Farmakiotis D, Kouraki K, et al. Forced expiratory volume in one second and peak expiratory flow rate values in nonprofessional male tennis players. J Sports Med Phys Fitness 2006:46:128-31.

17. Guenette JA, Witt JD, McKenzie DC, et al. Respiratory mechanics during exercise in endurance-trained men and women. J Physiol 2007;581:1309-22

18. Khosravi M, Tayebi SM, Safari H. Single and concurrent effects of endurance and resistance training on pulmonary function. Iran $\mathrm{J}$ Basic Med Sci 2013;16:628-34.

19. Maiolo C, Mohamed El, Carbonelli MG. Body composition and respiratory function. Acta Diabetol 2003;40(Suppl 1):s32-s38.

20. Mazic S, Lazovic B, Djelic M, et al. Respiratory parameters in elite athletes-does sport have an influence? Rev Port Pneumol 2015;21:192-7.

21. Cotes JE, Chinn DJ, Reed JW. Body mass, fat percentage, and fat free mass as reference variables for lung function: effects on terms for age and sex. Thorax 2001;56:839-44.

22. Price OJ, Ansley L, Menzies-Gow A, et al. Airway dysfunction in elite athletes-an occupational lung disease? Allergy 2013;68:1343-52.

23. Stocks J, Quanjer PH. Reference values for residual volume, functional residual capacity and total lung capacity. Eur Respir $J$ 1995;8:492-506.

24. Parsons JP, Mastronarde JG. Exercise-induced bronchoconstriction in athletes. Chest 2005;128:3966-74.

25. Lazovic-Popovic B, Zlatkovic-Svenda M, Durmic T, et al. Superior lung capacity in swimmers: Some questions, more answers!. Rev Port Pneumol 2016;22:151-6. 